\title{
Influence of additives on flexural strength of concrete
}

\author{
Sergii Tolmachov ${ }^{1, *}$, Olena Belichenko ${ }^{1}$, and Denis Zakharov ${ }^{1}$ \\ ${ }^{1}$ Kharkov National Automobile und Highway University, Department of the Technology of Road \\ Building Material and Chemistry, Yaroslava Mudrogo st. 25, 61002 Kharkov, Ukraine
}

\begin{abstract}
In earlier studies, the effect of chemical and mineral additives on the compressive strength of concretes was considered, but little attention was paid to the flexural strength of concrete. However, monolithic concretes of transport purpose, including road concretes, operate under conditions of tensile loads, which lead to their destruction. Therefore, it is actual to analyze the effect of superplasticizers, especially carboxylate type, as well as mineral additives and their complexes on the flexural strength of concrete. The article shows the results of studies for determining the influence of a superplasticizer of a carboxylate type, microfiller and fiber on the flexural strength of concrete. The influence of the time for maintaining a concrete mixture on the physical and mechanical properties of concrete is shown. The article shown that the addition of the mineral additive into the concrete mixture leads to an increase of flexural strength to $13 \%$. The use of an organomineral complex leads to an increase the early flexural strength of concrete to $37 \%$, and at the age of 28 days - to $20 \%$. The use of the complex of additives and polypropylene fibers results in an insignificant increase of the flexural strength in comparison with concretes containing only a complex of additives.
\end{abstract}

\section{State of the issue}

\subsection{Analysis of studies and publications}

Numerous studies carried around the world have shown the high efficiency of using superplasticizing additives in the technology of heavy cement concretes [1 - 4]. Their use makes it possible to change the nature of the colloid-chemical processes occurring in hardening cement binders. This fundamentally changes the properties of concrete mixtures and the safety of these properties in time. Essentially the properties of concrete are changing, for example, their physical and mechanical characteristics are improved, durability is increased. This is typical for all types of superplasticizers that are currently used. For example, purified lignosulfonates and their complexes with superplasticizers of other types. And also naphthalene- formaldehyde or melamine-formaldehyde superplasticizers, polyacrylate and polycarboxylate superplasticizers. The appearance of polycarboxylates and their wide use made it possible to return to the technology of heavy

\footnotetext{
* Corresponding author: Tolmachov.serg@gmail.com
} 
concrete with dispersed mineral additives, the use of which was widely studied in the 70$80 \mathrm{~s}$ of the last century [5-7].

These include additives such as metakaolin and microsilica. The complex of superplasticizer + mineral additive got the name organomineral complex. The use of these complexes alters the rheological properties of concrete mixtures, reduces their delimitation, and increases the density. This also leads to an increase in the strength properties of concrete, however, does not always improve their performance over time. This particularly applies to road concrete and transport concrete, which operate under difficult operating conditions.

In earlier studies, the effect of chemical and mineral additives on the compressive strength of concretes was considered, but little attention was paid to the flexural strength of concrete. However, monolithic concretes of transport purpose, including road concretes, operate under conditions of tensile loads, which lead to their destruction. Therefore, it is actual to analyze the influence of superplasticizers, especially carboxylate type, as well as mineral additives and their complexes on the flexural strength of concrete.

It is known that to increase the tensile strength of concrete, including the flexural strength, you can add fiber to their composition. It is also known that the use of polymeric or basalt fiber leads to a decrease of the compression strength of concrete [8-10]. Data on the effect of polypropylene fiber on the flexural strength of concrete are contradictory. In some articles it is shown that fiber increases flexural strength by $10 \ldots 15 \%$, in others - by tens of percent. There is no information about the joint effect of organomineral complexes and fiber on the flexural strength of concrete.

\subsection{Relevance}

This state of the question makes research actual about the effect of superplasticizers of the carboxylate type, mineral additives, polypropylene fibers and their complexes on the flexural strength of monolithic concretes.

\section{Materials and methods of research}

Were used: the cement of the PC I-500-N (CEM I 52.5N) of the Ivano-Frankivsk plant, crushed stone fr. 5-10 mm, river sand was used.

In concrete mixtures were added:

- chemical additive - superplasticizer of carboxylate type Sika Plast 2508 (SP) produced by the Swiss company Sika (1\% of the mass of cement );

- mineral additive "Universal VM" (MA) produced by the Ukrainian Zaporozhye firm "Budindustria" (7 \% of the mass of cement);

- polypropylene fiber (F) produced by the Ukrainian Dnepr company "Spetssnab" (1 kg per $1 \mathrm{~m}^{3}$ of concrete mix).

The mixture of concrete: cement $-350 \mathrm{~kg} / \mathrm{m}^{3}$, sand $-600 \mathrm{~kg} / \mathrm{m}^{3}$, rubble $-1300 \mathrm{~kg} / \mathrm{m}^{3}$.

The flexural strength of concrete was studied on the samples-beams measuring $4 \times 4 \times 16$ and $7 \times 7 \times 28 \mathrm{~cm}$. The compressive strength of concrete was studied on samples-cubes with a size of $7 \times 7 \times 7 \mathrm{~cm}$.

\section{Experimental research}

Investigations of the effect of various additives on the strength of concrete were carried out on equally mobile concrete mix in the Table 1 .Studies have shown that when the mineral additive is added into the concrete, strength increases, but for compressive strength and 
flexural strength this increase is different. The compressive strength of concrete with a mineral additive increases by only $3 . . .6 \%$ at different times of hardening. At the same time, the flexural strength of concrete with a mineral additive increases by 18,10 and $8 \%$ on 3,7 and 28 days, respectively.

Table 1. Strength of concretes with additives

\begin{tabular}{|c|c|c|c|c|c|c|c|}
\hline \multirow[t]{2}{*}{ Type of additive } & \multirow[t]{2}{*}{$\mathrm{W} / \mathrm{C}$} & \multicolumn{3}{|c|}{$\begin{array}{l}\text { Flexural strength at } \\
\text { the age, days, } \mathrm{R}_{\mathrm{fs}}, \mathrm{MPa}\end{array}$} & \multicolumn{3}{|c|}{$\begin{array}{l}\text { Compressive strength at } \\
\text { the age, days., } \mathrm{R}_{\mathrm{cs}}, \mathrm{MPa}\end{array}$} \\
\hline & & 3 & 7 & 28 & 3 & 7 & 28 \\
\hline Without additive & 0.5 & 5.1 & 6.0 & 7.0 & 32.3 & 39.1 & 51.2 \\
\hline MA & 0.5 & 6.0 & 6.6 & 7.9 & 34.4 & 40.0 & 53.0 \\
\hline $\mathrm{CP}+\mathrm{MA}$ & 0.42 & 7.0 & 7.6 & 8.4 & 44.4 & 53.9 & 68.3 \\
\hline $\mathrm{CP}+\mathrm{MA}+\mathrm{F}$ & 0.43 & 6.9 & 7.9 & 8.8 & 40.1 & 50.4 & 61.7 \\
\hline
\end{tabular}

* the mobility of concrete mixes corresponded to grade P1

This increase of flexural strength, relative to the increase in compressive strength, may indicate that the filler microparticles compact and harden, in the first place, the contact zone "hardening cement paste - aggregate" due to the formation of low-basic hydrosilicates. This zone is responsible for the tension strength of concrete, its hardening leads to an increase of the flexural strength. It should also be noted the tendency to reduce the growth of the flexural strength with increasing hardening time. This can be caused by gradual hardening, both the contact zone and the hardening cement paste both in concretes without additives and with the addition of a microfiller.

The introduction of the organomineral complex leads to an increase of the compressive strength of concrete by $38 \ldots 34 \%$, compared to the composition without additives at all times of hardening. The flexural strength increases by 39,25 and $11 \%$ at the age of 3,7 and 28 days, respectively. This confirms the information obtained earlier. The increase of compressive strength is due to a reduction in the water content of concrete. There is also a gradual decrease of growth of flexural strength caused by the gradual strengthening of the contact zone in time, regardless of the presence or absence of additives.

The results of our experiment show that in concretes containing an organomineral complex + polypropylene fiber there is a decrease of the compressive strength of concrete, in comparison with the strength of concretes that do not contain fiber. This decrease is 11,7 and $11 \%$ at the ages of 3, 7 and 28 days of hardening.

At the same time, despite a slight (not more than $3 \%$ ) reduction of flexural strength at the age of 3 days, concretes containing an organomineral complex and a fiber, have a higher flexural strength at the age of 7 and 28 days of hardening compared to concrete that does not contain fiber. The difference in strength is 5 and $9 \%$. This can be explained by the fact that polypropylene fiber reinforces the intergranular space of concrete, which leads to an additional increase of the flexural strength of concrete, in comparison with the effect of only the organomineral complex.

Also, studies were carried out for the effect of maintaining time of the concrete mixture after preparing on the strength of the obtained samples in Table 2.

Concrete mixtures were made and the slump of the concrete mix was measured. After that, samples of concrete were made. Then mixture residue was cured for 45 minutes, then mixed and the slump was measured again, and the samples were also molded.

The same operation was repeated after 90 minutes of maintaining the mixture. 
The experiment results showed that the compressive strength of the concrete samples without additives that were made immediately after the making of the mixture was lower than the samples that were made after 45 minutes of maintaining the mixture. At the age of 3 and 7 days, this difference was up to $5 \%$. It can be noted that by the 28 days of hardening the compressive strength of both samples is the same. The strength of the samples made of concrete mixtures aged 90 minutes is less by $2 \ldots .4 \%$ compared to the samples made immediately after the preparation of the mixture. This can be explained by the effect of "remixing" or "re-vibrating" [11].

Table 2. Influence of the maintaining time of the concrete mixture on the strength of concrete

\begin{tabular}{|c|c|c|c|c|c|c|c|c|}
\hline \multirow[t]{2}{*}{$\begin{array}{l}\text { Measurement } \\
\text { time, min }\end{array}$} & \multirow[t]{2}{*}{ Additive } & \multirow{2}{*}{$\begin{array}{l}\text { Slump } \\
\text { of } \\
\text { concrete } \\
\text { mix, sm }\end{array}$} & \multicolumn{3}{|c|}{$\begin{array}{c}\text { Flexural strength at } \\
\text { the age, days, } \mathrm{R}_{\mathrm{fs}} \text {, } \\
\mathrm{MPa}\end{array}$} & \multicolumn{3}{|c|}{$\begin{array}{l}\text { Compressive strength at } \\
\text { the age, days, } \mathrm{R}_{\mathrm{cs}}, \mathrm{MPa}\end{array}$} \\
\hline & & & 3 & 7 & 28 & 3 & 7 & 28 \\
\hline \multirow{2}{*}{$5 \mathrm{~min}$} & - & 8.5 & 5.2 & 6.4 & 7.3 & 28.3 & 34.8 & 44.2 \\
\hline & $\mathrm{CP}$ & 7 & 6.6 & 7.7 & 8.0 & 39.7 & 47.8 & 61.8 \\
\hline \multirow{2}{*}{$45 \mathrm{~min}$} & - & 4 & 5.5 & 6.6 & 7.4 & 29.2 & 36.7 & 44.6 \\
\hline & $\mathrm{CP}$ & 5 & 6.3 & 7.5 & 8.4 & 43.5 & 50.4 & 63.0 \\
\hline \multirow{2}{*}{$90 \mathrm{~min}$} & - & 1 & 5.4 & 6.1 & 7.4 & 27.4 & 34.3 & 42.5 \\
\hline & $\mathrm{CP}$ & 4 & 6.1 & 7.2 & 8.2 & 42.2 & 48.3 & 61.7 \\
\hline
\end{tabular}

*Initial $\mathrm{W} / \mathrm{C}$ in a concrete mix without the additive was 0.55 , with the additive -0.46

It is known that in the process of cement hydration, an unstable, mainly hydroaluminous structure of cement stone is formed. After a certain time of maintaining the mixture and then applying vibration or mixing, this structure breaks down. As a result, a large number of additional crystallization centers appear in the volume of the hardening cement paste. This helps to accelerate the growth of strength, especially in the early stages of hardening. But applying such external influences is necessary at a strictly certain moment, otherwise, this may lead to the opposite result. The decrease in strength can be observed in samples from a concrete mix that has been aged for 90 minutes. The small difference in the strength of the samples from a mixture aged 45 minutes, as compared to the samples that were made immediately after the mixture was made, can also be explained by too late applying of a re-mixing of the mixture than was necessary.

The compressive strength of samples made from mixtures with a superplasticizer and kept for 45 minutes is higher than for samples prepared immediately after the preparation of the mixture. It is 10 and $5 \%$ at the age of 3 and 7 days. But by 28 days of hardening, this difference is reduced to $2 \%$. The growth of strength between the samples molded from the mixture, which was kept for 90 minutes and molded immediately is much less: 6 and $1 \%$ on days 3 and 7. A small increase in strength can be explained by the retarding effect of the action of carboxylates at the initial stage of hardening.

The flexural strength of samples of concrete without additives that were made at different times is practically the same in all observed hardening periods. In concrete containing the additive of the superplasticizer, it is possible to observe a decrease in flexural strength in samples that were made from pre-aged concrete mixtures. The difference in strength was $7 \ldots 8 \%$ compared to the strength of the specimens molded 
immediately. This can be explained by the fact that the zone of contact "hardened cement paste - aggregate" is also destructed during the re-mixing. Since in the initial period of hydration of cement because of the presence of a superplasticizer, the rate speed of formation of the structure in the contact zone slows down, then this deceleration has a greater effect on flexural strength.

\section{Conclusion}

1. It is shown that adding a mineral additive into the concrete mixture leads to an increase of flexural strength to $13 \%$, while the compressive strength increases by no more than $6 \%$.

2. The use of an organomineral complex leads to an increase the early flexural strength of concrete to $37 \%$, and at the age of 28 days - to $20 \%$. At the same time, the compressive strength of concrete increases to $37 \%$ during all test periods.

3. The use of the complex of additives and polypropylene fibers results in an insignificant increase of the flexural strength in comparison with concretes containing only a complex of additives - up to $4 \%$. The compressive strength of such concretes is reduced to $11 \%$.

4. It has been established that keeping the concrete mixture for 45 to 90 minutes before starting the molding of the samples slightly changes the flexural strength and compressive strength of concrete without additives. But such maintaining primarily leads to a reduction of the flexural strength of concretes containing a superplasticizer to $8 \%$.

\section{References}

1. P.C. Aitchin, High Performance Concrete (London: T\&F e-Library, 2004)

2. H. Nakanishi, S. Tamaki, ACI SP, 217, 327-342 (2003)

3. V.S. Izotov, R.A. Ibragimov, Technologies of concrete, 3-4, 34-34 (2012)

4. S.N.Tolmachev, Highways, 12 (1009), 54-57 (2015)

5. V.I. Kalashnikov, E.V. Gulyaeva, D.M. Valiev, V.M. Volodin, A.V. Khvastunov, Construction Materials, 11, 44-47 (2011)

6. V.R. Falikman, Concrete and Reinforced Concrete, 1, 48-54 (2011)

7. S.N. Tolmachev, E.A. Belichenko, Bulletin of ODABA, 61, 392-397 (2016)

8. Milind V. Mohod, IOSR-JMCE, 12, 28-36 (2015). DOI: 10.9790/1684-12112836/

9. S.N. Tolmachev, E.A. Belichenko, Building materials and products, 1 (91), 76-79 (2016)

10. F.N. Rabinovich, Composites based on dispersed-reinforced concrete. Questions of theory and design, technology, design [Monograph] (Moscow, ASV, 2004)

11. Kh.V. Abazov, Road concretes on sand-gravel aggregates from re-blended mixtures. Cand. Diss. (Engineering). Kharkov. 143 (2003) 